\title{
Space weather climate impacts on railway infrastructure
}

\author{
Adithya Thaduri ${ }^{1}$ (i) $\cdot$ Diego Galar ${ }^{1} \cdot$ Uday Kumar $^{1}$
}

Received: 28 August 2019/Revised: 4 June 2020/Published online: 17 June 2020

(C) The Author(s) 2020

\begin{abstract}
Space weather is a phenomenon in which radioactivity and atomic particles is caused by emission from the Sun and stars. It is one of the extreme climate events that could potentially has short-term and long-term impacts on infrastructure. The effects of this phenomenon are a multi-fold process that include electronic system, equipment and component failures, short-term and longterm hazards and consequences to astronauts and aircraft crews, electrostatic charge variation of satellites, disruptions in telecommunications systems, navigational systems, power transmission failures and disturbances to the rail traffic and power grids. The critical infrastructures are becoming interdependent to each other and these infrastructures are vulnerable if one of them is affected due to space weather. Railway infrastructure could be affected by the extreme space weather events and long-term evolution due to direct and indirect effects on system components, such as track circuits, electronic components in-built in signalling systems or indirectly via interdependencies on power, communications, etc. While several space weatherrelated studies focus on power grids, Global Navigation Satellite System (GNSS) and aviation sectors, a little attention has focused towards probability of railway infrastructure disruptions. Nevertheless, disruptions due to space weather on signalling and train control systems has documented but other systems that railway infrastructure
\end{abstract}

Adithya Thaduri

Adithya.thaduri@1tu.se

Diego Galar

diego.galar@1tu.se

Uday Kumar

uday.kumar@1tu.se

1 Luleå University of Technology, Luleå, Sweden dependent upon are not very well studied. Due to the advancements in digitalization, cloud storage, Internet of Things (IoT), etc., that are embedded with electronic equipment are also possible to prone to these effects and it is even become more susceptible to the extreme space weather events. This paper gives a review of space weather effects on railways and other transportation systems and provide some of the mitigation measures to the infrastructure and societal point of view.

Keywords Solar storms - Railways - Transport - Space weather . Climate

\section{Introduction}

From the historical record of the environment, the ecosystem of earth like living beings, infrastructure and nature are prone to the extremities of weather related to earthquakes, droughts and floods, ice storms, hurricanes, cyclones, tsunamis, and tornados. There are some rare catastrophic events such as asteroids, comments, solar flares or other space objects that enter earth's field affects the environment. These events have severe disruptions to the upper atmosphere and near-Earth space environment guided by the magnetic movement of Sun and create disruptions to the existing infrastructure by a change in Earth's magnetic field. Owing to the development of new technologies, telephone, internet and radio communications, and interdependence on space-based communications and navigation, the necessity of transportation systems, the susceptibility of recent society and its technological infrastructure to "space weather" has increased intensely. Sensing the Sun-Earth system has become more 
serious as satellites and human activity in space have become more common.

Space weather is a term used to describe the variations in the Sun, solar wind, ${ }^{1}$ ionosphere, ${ }^{2}$ magnetosphere ${ }^{3}$ and thermosphere, ${ }^{4}$ that can influence the performability and dependability of a variety of spaceborne and ground-based engineering systems and also threaten human health and safety (Koons et al. 1999). Ionosphere layer is exceedingly vital for telecommunication systems, as it impacts the movement of radio waves. At higher latitudes, there is an extra source of ionization of the ionosphere associated with-the aurora. The high-speed electrons and protons, arriving from the magnetosphere and rising down the Earth's magnetic field lines causes the aurora.

Space weather originates primarily from solar activity and emitting optical and near-infrared radiation. During solar disturbances, there is significant deviation across a range of wavelengths (e.g. Extreme Ultraviolet Radiation (EUV), X-Ray, and radio) because of the release of solar energetic particles. These particles from the Sun during space weather events affect currents of fluctuating intensity in the ionosphere and magnetosphere. The currents generate a magnetic field whose time variations stimulates a geoelectric field that in turn, produces currents in the conductors including Earth and ground-based technical networks. This includes electric power grids, oil, sewer and gas pipelines, radio and telecommunication cables and railway systems (Watermann 2007).

These currents are known as "geomagnetically induced currents (GIC), which are thus ground effects of space weather. These are known as, and their induction can occur in any long surface conductors or through the Earth's surface. In summary, the stream of GIC can be described using Faraday's and Ohm's laws as follows: “time-varying currents in the near-earth space create temporal variations of the geomagnetic field". It should be noted that the geomagnetic variation and the geo-electric field are primarily created by space currents, but currents induced in the Earth also give an important secondary contribution.

A solar storm represents atmospheric effects observed on Earth from solar events that occur on the Sun. Solar storms create strong currents in the magnetosphere, fluctuations in the radiation belts and variations in the ionosphere, involving the heating of the ionosphere and the

\footnotetext{
1 The continuous flow of charged particles from the sun which permeates the solar system.

${ }^{2}$ In general, the ionosphere contains only a small fraction of the Earth's atmosphere (above $100 \mathrm{~km}$ there $<1 \%$ of the mass of the atmosphere)

3 The magnetosphere is formed by the interaction of the solar wind with Earth's magnetic field.

${ }^{4}$ thermosphere extends from about $90 \mathrm{~km}$ (56 miles) to between 500 and $1000 \mathrm{~km}$ (311-621 miles) above our planet.
}

upper atmosphere region known as the thermosphere. During solar storms, the currents in the ionosphere and the energetic particles that cause them into the ionosphere add energy in the form of heat that can rise the density and distribution in the earth orbit. Usually, these variations of the Earth's ionosphere will influence radio transmissions in the high-frequency band (HF) since they use the ionosphere to reflect the radio wave back to Earth. These solar events include the phenomena and events as illustrated in Fig. 1(Moldwin 2008):

- Solar flares: are the flares of X-Rays and other electromagnetic radiation.

- Coronal mass ejections (CME): are high-speed bursts of denser solar matter. Hot matter erupts out of the Sun's atmosphere and into interplanetary space that taking about four and a half days to reach the Earth. The impact of CMEs on the Earth is a complicated process intensely affected by the alignment of magnetic fields.

- Solar radiation storms: enhanced fluxes of energetic charged particles.

- Solar radio bursts: strong bursts of natural radio emissions.

- Solar wind: corpuscular radiation, charged atoms and sub-atomic particles emissions.

The American National Oceanic and Atmospheric Administration (NOAA) predicted that 'minor' geomagnetic storms happens around 1700 times for the duration of a 11-year cycle, influencing 900 days; with an 'extreme' geomagnetic storm ${ }^{5}$ happening at 4 times for the duration a cycle, influencing 4 days. These events do not only include strong currents but also currents of medium and weak strength and there is an insufficient knowledge or information on these minor currents. Due to the stochastic behaviour of these events, it is hard to predict and when they will happen and prevent them but, it is probable to see a common trend (Grant et al. 2012).

\section{Effects on infrastructure and society}

There is a complexity of the past and present technological infrastructure and over dependent on electronic systems that has applications in connectivity, data storage and operations. These systems can have impacts of severe space weather events and precautionary measures are often mainly dependent on the experience and knowledge gained from the past few events on various technologies (Baker

\footnotetext{
5 A geomagnetic storm is a short-term disruption to the Earth's magnetosphere that is triggered by a solar wind shock wave and/or cloud of magnetic field that interacting with the Earth's magnetic field. The growth in the solar wind pressure primarily squeezes the magnetosphere.
} 


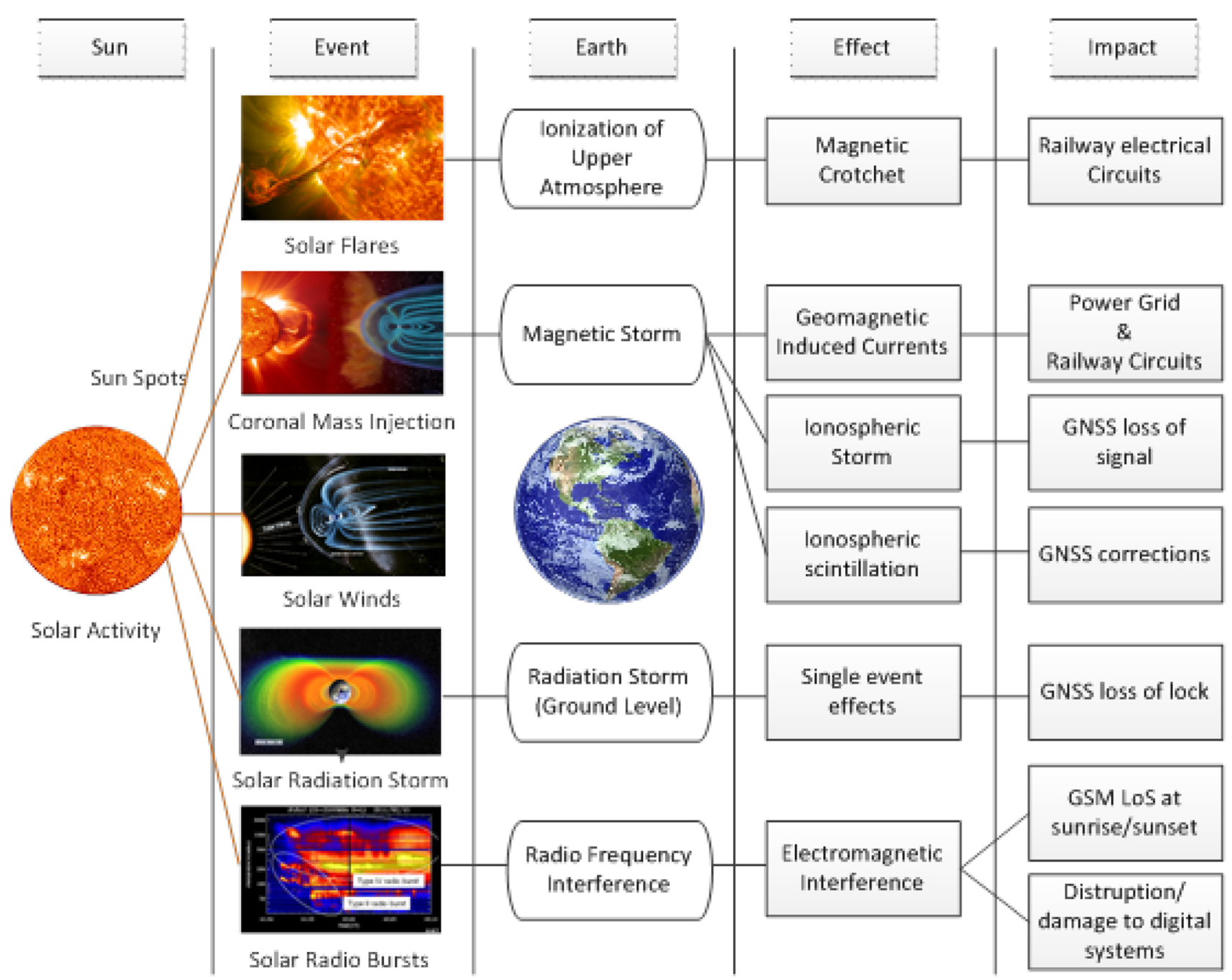

Fig. 1 Solar activities and effects in the solar system

and Lanzerotti 2016; Vennerstrom et al. 2016). In addition, there is also an increasing trend on awareness of climatic events and climate adaptations of these infrastructure, space weather is becoming major attention in upcoming days (Patt et al. 2013).

From the time of monitoring of storm activity, the largest recorded event occurred between August 27 and September 7, 1859 and named as the 'Carrington Event' that disrupted telegraphs worldwide. Such type of events at present can disrupt not only electric power grids but also can disrupt the whole infrastructure. These events can cause short-term operational anomalies due to exposure to spacecraft by energetic particles and radiation belt in addition to destruct crucial electronic equipment deteriorate solar arrays and mask optical systems such as imagers and star trackers (Baker et al. 2004).

The initial awareness and knowledge of the social, ecological, and economical consequences and repercussions of space weather is increasing but is still elementary.
In addition, it also necessary to understand and evaluate the consequences causing disruptions of individual and interdependencies of infrastructure due to space weather. Usually, space weather events are considered as a lowfrequency/high-consequence (LF/HC) event. These events can have potential to become a significant impact and difficult to process and develop appropriate plans for managing with these events. Due to its behaviour, it is also difficult to plan and provide budgets for rehabilitation and contingencies and enough management capability to counter those events that encounters the foundation for traditional policies and risk management. In addition, social and other institutional reactions to space weather events necessitate a separate and unique methodology than technical system responses (Board 2008). 


\subsection{Effects in secondary systems}

Critical infrastructures depend on several subsystems that are interdependent that work towards the goals of the society. However, these subsystems can also be vulnerable to the space weather events and are briefed below:

\subsubsection{Navigation systems}

Harmful outcomes of the equatorial position in ionospheric abnormalities on satellite-based communication systems and navigation systems have been explored and examined over the past years as space weather events have the capability to critically interrupt the technological infrastructure of current-day civilisation (Roy and Paul 2013; Hapgood 2017).

\subsubsection{Power systems}

The critical infrastructure that society has become most reliant on is the power grid (Boteler et al. 1998). The impact of space weather on the power grid systems is a substantial and recurrent hazard with possibly severe consequences on the society. Since power systems are the major subsystems, there is a need for better preparedness to reduce the GIC impacts. In some countries like Finland, models and tools were developed to predict and assess the impacts of these events on the power grids. In some countries, the transmission grids were less prone to these events (Krausmann et al. 2013). There were significant effects like transformer saturation, reactive power losses, harmonics, transformer heating, generator overheating and protection relay tripping due to space weather events in power systems (Piccinelli and Krausmann 2014). These events also could affect the economic value of power grids (Eastwood et al. 2018).

\subsubsection{Pipelines infrastructure}

Pipelines, especially that are underground or underwater are usually protected from corrosion and other primary effects by preserving them at a negative electrical potential w.r.t the ground. At the event of a magnetic storm, the electric field caused along the pipeline may neutralize the utilized prospective, take away the protection of corrosion and probably even speeding up of corrosion process (Cander 2019; Pirjola et al. 1999; Trichtchenko and Boteler 2001).

\subsubsection{Radio communications}

Space weather effects radio communication in different ways. From the radio frequencies within the range from 1 to $30 \mathrm{MHz}$ range (known as "High Frequency"), the variations in ionospheric density and structure alter the transmission path and even prevent transmission of $\mathrm{HF}$ radio signals totally. The increased D-layer due to ionization by solar flares acts as a reflector of radio waves at various frequencies and an absorber at the additional frequencies that will lead to blackout condition (Pesnell 2015).

\subsubsection{Telecommunication cables}

Initially, long distance telecommunication cables were perhaps the first human technology to be influenced by space weather called 'Carrington event' happened during mid-19th century where "anomalous currents" flowed in telegraph cables (Lanzerotti 2001a). Recently, the operation of a transatlantic cable was also rigorously disturbed during the magnetic storm of 13-14th March 1989. Generally, long-distance telecommunication cables comprise of optical fibres instead of wires, the direct effects due to geomagnetically induced electric field becomes negligible that previously. Daglis et al. (2019) has also provided their impact of space weather events on the economic activity and its effect on telecommunications. Nevertheless, the power supply to signal amplifiers all along the length of the cable must be modified in order to manage with GIC currents. In that aspect, space weather models can facilitate for defining and identifying design parameters (Goodman 2006; Clark 2001).

\subsection{Interdependence on the society}

Modern-day technological society is shown by a complex intertwine of dependencies and interdependencies among its several critical infrastructures as shown in Fig. 2. The analysis of susceptibilities due to interdependencies of railway systems on the other systems in case of Swedish Railway transport was conducted by (Johansson et al. 2011). As the national and international infrastructures and services grown exponentially in complexity, design and interdependence over time, any major disruption of one of the infrastructures can have a seemingly widespread impacts on the other infrastructures. Services includes provisioning of backup that needs to be adequately separated from each other that a single event or possibly much numerous events could not instantaneously closed on other locations. Interestingly, railways could also impact on other infrastructures such as pipeline infrastructure that influence inter-dependent failures (Garmabaki et al. 2020). It was also stated that the impacts on these interdependent infrastructures might continue for multiple years in future, with a possibility for substantial societal and economic impacts that could be quantifiable in the numerous trillion 


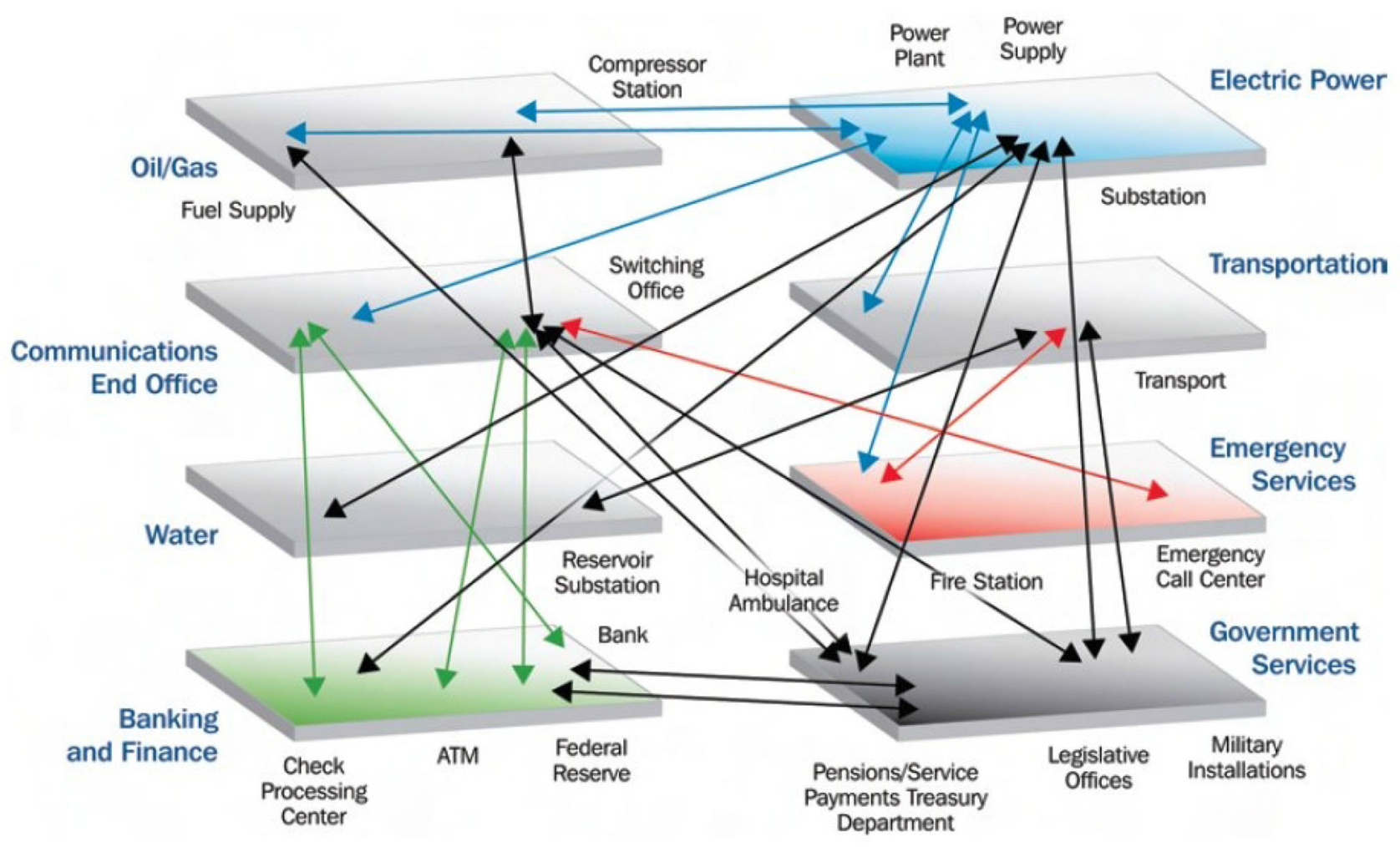

Fig. 2 Interdependence of systems on the society

per-year range (p. 30, Board 2008; Oughton et al. 2017). In case of disruptions to the telecommunication systems, it could have long standing disruptions to the other dependent infrastructures such as transportation, power, internet, etc. (Forte et al. 2018).

\section{Effects on railway infrastructure}

Railway transport majorly depends on the availability of other critical infrastructures such as power, signalling, communications, and navigation systems for operations and positioning and the previous studies showed that these technologies were and could be disrupted during space weather. Due to the introduction of digitalized railways, such as big data (Thaduri et al. 2015), maintenance 4.0 (Kans et al. 2016), Internet of things (IoT) (Jo et al. 2017), cyber-physical systems (Thaduri et al. 2020), there may also be disruptions of other digital electronic equipment within vehicles and infrastructure. Railway signalling could be affected as well (Pirjola 2005). Technological advancements have increased the risk of adverse effects caused by the solar storm. Previously, the steam trains were not exposed to the solar storm, but the current electric trains are extremely susceptible. In addition, railways can drive reverse back additional currents into railway signalling systems from the track circuits due to insufficient isolation (communicated via the long rails). This is basically the similar phenomenon as the currents that destabilize power grids in the event of major magnetic storms (Eroshenko et al. 2010).

The rail sector's power-grid dependency is a critical vulnerability because of its immediate impact on the railway network, but power failure can also affect other systems in the station. From a safety criticality standpoint, the most significant systems that may be affected by GIC are signalling and traffic control systems. This problem exists due to the increase in lengths of track-circuit and longer length of trains. The other problems related to the variation in alternating current (AC)/direct current (DC) rail systems also need to be taken into account (Girgis and Vedante 2012). Other railway equipment such as heating systems, switching actions can also be possibly susceptible to GIC are wayside cables, telecom and line-side circuits, backup systems, batteries, condition monitoring systems, point circuits in switching and crossings and location cabinets (Krausmann et al. 2015).

Looking into the outlook, advanced train control technologies, like European Train Control System (ETCS) and European Railway Traffic Management System (ERTMS) also dependent on communications channels using mobile phone and wireless technology. They are conceivably susceptible to interference from solar radio bursts. These communication channels facilitate trains to transmit their 
speed and position to control centres using mobile and wireless technology and for those centres to communicate movement to trains. Interference from radio bursts could break the control communications leading to halting movement of railways and could disrupt railway schedules. There has been reduced influence on the solar maximum from 2012 to 2015, but these systems might expose more predominant effects by next solar maximum (2024) that lead to higher risk. The present developers and potential users of the technology must perform experiments to monitor solar storm problems on the current systems and search for solutions for long-term impacts (Lanzerotti 2001a, b, b).

\subsection{Swedish railway infrastructure}

Railway infrastructure comprises of large area and usually difficult to operate and maintain provided its complexity, number of stakeholders, weather fluctuations, government regulations, unexpected demands, and its interdependencies on other critical infrastructures (Johansson et al. 2011). Trafikverket is mainly responsible for the long-term infrastructure operation, maintenance and renewal planning of road, rail, sea and air transport in Sweden.

\subsection{Review of space weather events}

Although GICs have probably disturbed railway infrastructure frequently, rather, there are only few instances of cases (Wik 2008) including a problem in Swedish railways in July 1982 reported by Wallerius (1982). In this case, there was a technological effect of an unexpected change in traffic light. In usual conditions, in the absenteeism of a train, a battery maintains a DC voltage of $3-5 \mathrm{~V}$ between the rails and over relay and becomes energized. A second circuit was disturbed by the relay and it was in connection to the traffic lights; it indicates that the light is green when the relay is energized, while a de-energized relay generates a red light. At the night between 13-14th July 1982, the traffic lights turned automatically from green to red without any apparent reason in a $45 \mathrm{~km}$ long railway track section in the southern part of Sweden. After a certain period of time, the lights turned again from green to red again. In the presence of train, the axles of the train bogies short-circuit the rails creating a voltage of zero hence de-energizing the relay and turning to a red light (Wik et al. 2009) as shown in Fig. 3. This event has headed to few more researches in Swedish Transport infrastructure (Trafikverket) (Fällman 1999; Wästgärds 2000). These records provided more information of space weather events on different subsystems in Swedish railways.

A similar case on the effect of solar storm events on the railway systems was provided by Lam et al. (2002). On
October 2003, the GIC effects on the Swedish power system located in southern part, Malmo, resulting in a power failure in addition to the predominant space and geophysical conditions, as explained by Pulkkinen et al. (2005) and Lundstedt (2006). Swedish ground-based railway networks have endured from GIC impacts on numerous other incidents (e.g. Elovaara et al. 1992; Boteler et al. 1998; Lundstedt 2006).

While the research remains limited, Boteler et al. (1998) explained the effects of geomagnetic disruptions on electrical power systems. A prediction of GIC in power systems was provided by Pirjola (2000). Lundstedt (2006) provides a brief explanation of the susceptible Swedish power system (because of its proximity to the aurora area and pipeline system), in addition to the past explanation geomagnetically induced currents effects, from the Halloween events in 2003 to November 2004. It was coming to know that Sweden has faced GIC impacts is reasonable because of the country's location at the high latitude. Nevertheless, the vicinity to the aurora zone is not only the main reason for assessing GIC risk. The levels of GIC and the sensitivity of a system also are related to the structure of the system, resistances derived from the design and operation and other technical aspects of the railway network.

The scale of the induced currents and electrical fields are also dependent up on electrical conductivities of the various layers inside the earth crust. Magnetic fluctuation with shorter frequencies is usually permeate lower into the crust. These currents are majorly guided by the geoelectric field that is coupled with magnetic fluctuation in electric power grid networks, pipelines, communication cables and railway equipment. GICs add up to the standing currents and this will trigger saturation of the device's performance, raising to multiplied harmonics, needless tripping of relays, raising in reactive power loss, frequency and stochastic voltage drops, long-lasting damage to the power transformers and blackout of the complete system (Hanslmeier 2010).

\subsection{Space weather effects on railway systems}

There has been some evidence of effects of space weather on railway systems not only in Sweden but also in other countries such as Russia, Siberia, etc. as shown in Table 1. Some of the events could be affected by the space weather are listed below. There is also a lack of understanding of possible effects since these studies are at the initial stages of research. Due to criticality of these effects, there is a necessity to consider these issues in building robust systems. 

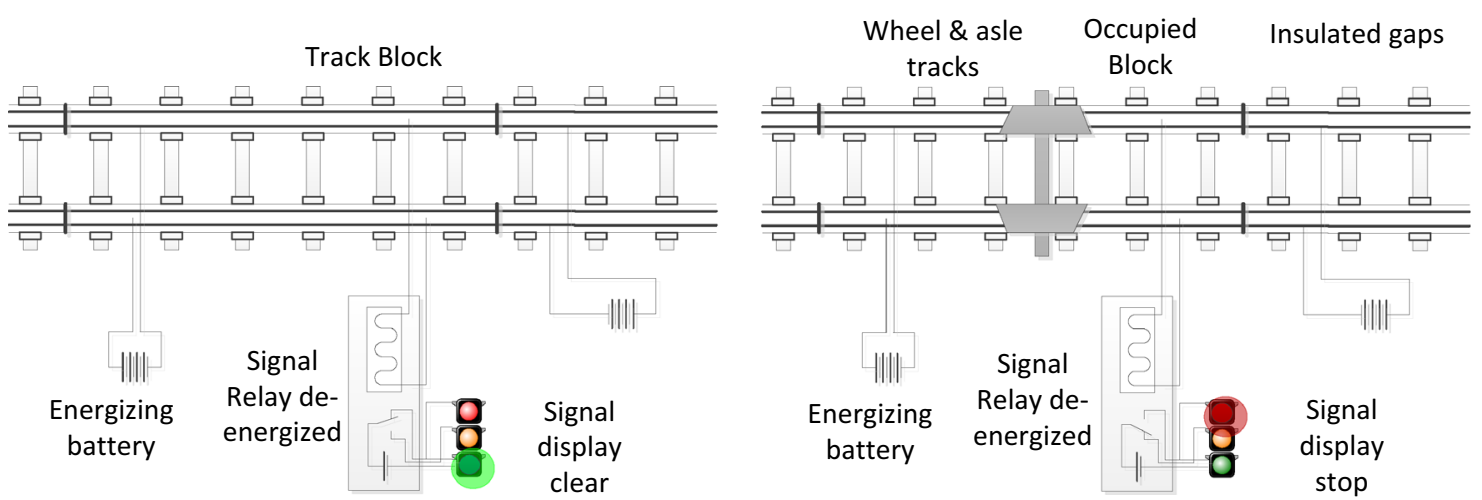

Fig. 3 Change of signal due to presence of wheel

Table 1 Space weather events on railways in several countries

\begin{tabular}{|c|c|c|}
\hline Year & Place & Event \\
\hline March, 1847 & UK & Spontaneous currents were noticed on the telegraphs on several other track sections of railway \\
\hline May, 1921 & $\begin{array}{l}\text { USA/ } \\
\text { Sweden }\end{array}$ & Telegraph explosion at the railroad station in New York and in Sweden a telephone station was burned out \\
\hline July, 1982 & Sweden & Railway signals were automatically turned from green to red by induced voltage \\
\hline March, 1989 & Russia & $\begin{array}{l}\text { Geomagnetic storm disturbed the automatic railway systems triggering several signals by reporting with false } \\
\text { obstructions of railway track }\end{array}$ \\
\hline April, 2000 & Russia & Unexplained anomalies in railway circuits in Russia were reported \\
\hline March, 2001 & Russia & Railway circuits described false tracks blockages with the high geomagnetic storm activity \\
\hline $\begin{array}{l}\text { October, } \\
2003\end{array}$ & Russia & Unexplained anomalies in railway circuits were observed \\
\hline $\begin{array}{l}\text { November, } \\
2004\end{array}$ & Russia & Signals suggesting false blockages in the railway tracks in Russia with random behaviour of signals \\
\hline
\end{tabular}

\subsubsection{Effects on railway bearings on the rolling stock}

A possible risk for rolling stock is corrosion due to additional electric current. Bearings, in general, are in a rotational mode, since the electric current goes all the way through a bearing causing arcing and burning. These effects happened on the thin oil film located at joints of contact between the raceway and rolling elements. The induced current can change the characteristics of the component and electromagnetic interference cause faults and failures in the Swedish Railway (Niska 2008). By observing the Kp-index (the index that represents the intensity of solar storm) and the failures of bearings in Swedish mine, we found that during the event on St.Patrick's day (17-18th March 2015), several bearings was failed as shown in Fig. 4. However, there is scope of further research on upcoming events. Morant et al. (2012) studied the impact of railway electro-magnetic interference (EMI) on railway train operation and environment and solar storms could affect EMIs.

\subsubsection{Railway power problems and their mitigation}

Measurable induced currents flowed in the earth and in long lengths electrical conductors either in overhead cables or track circuits. GIC induction destructs components in the power-grid, such as inductors, capacitors and high-voltage transformers that could results in the extended loss of power. These GICs and existing currents gradually change in a span of minutes to hours and might saturate power transformers of $1 / 2$ of $60 \mathrm{~Hz}$ cycle. This saturation results in increase of harmonics and eddy currents on the cables and wires in the power transformer leading to transformer heating. If there exists protective relays on power lines, then it usually doesn't trip that could lead to stability problems (Pulkkinen et al. 2005). The disturbances of geomagnetic storms in Swedish power systems are listed in (Kraftnät 2011).

Voltage fluctuations have been detected on feeding and relay circuits of the railway signalling system, and damage of traction current could halt trains which are electrically powered. Railway stations may also be influenced by a 

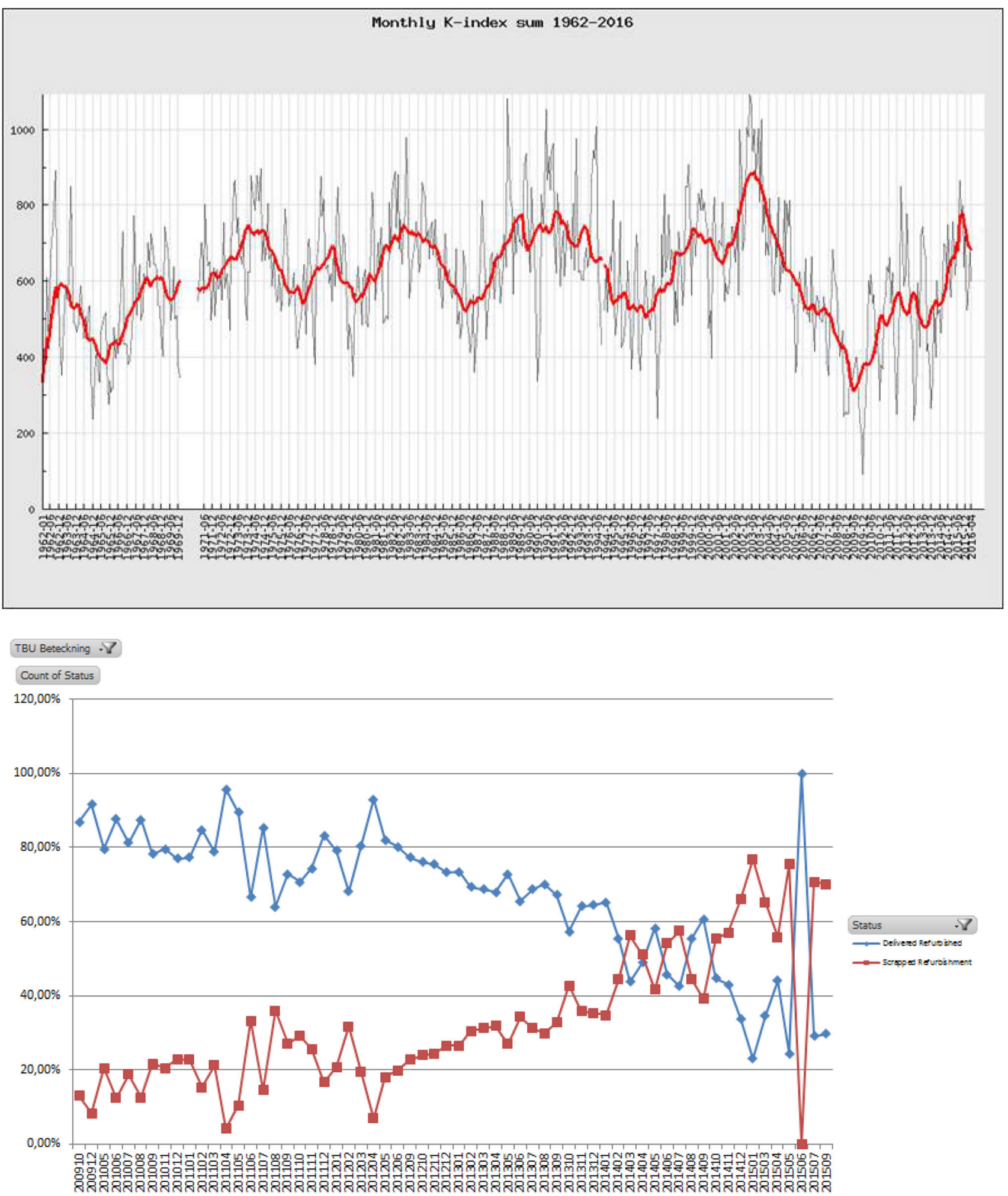

Fig. 4 (Top) Kp-index (Bottom) bearing failures; On December 2015, there was peak in bearing's refurbishments that correlates to kp-index. (Xaxis is the time and $\mathrm{Y}$-axis are the percentage of degradation of bearings)

power disruption (Krausmann et al. 2015). Nevertheless, the older transformers with absence of online condition monitoring, the presence of gas evolution and water content in the transformers could be a problem. Another option for monitoring the transformer is to detect the hottest point that would lead to the real time digital modelling 
of the transformer design, along with the GIC and AC voltage for that transformer. Hence, there is a need to monitor the transformers for all grid facilities that are being developed. A serious solar storm could spoil up to 300 EHV transformers, causing a lack of power for several years whilst additional transformers are manufactured and fitted (McMorrow 2011). An attempt has been made in Finland to understand the effects of solar storms on DC transformers (Pulkkinen et al. 2011). They are concerned of the danger caused by GICs and need to take necessary measures to prevent destruction in the grid itself, e.g., through suitable transformer specifications and requirements must be designed during acquisition (Kappenman 2010).

\subsubsection{Incorrect signal settings, risk of derailment and crashes}

Railway signalling is one of the most important systems in the railway infrastructure in terms of operation and safety. From the previous studies, there exists anomalies in signalling systems have been detected during geomagnetic storms. The failures on railway signalling would have severe consequences such as accidents due to false occupancy (Colla et al. 2018), effect on maintenance (Consilvio et al. 2019a, b) and vulnerability analysis of complex railway systems (Baglietto et al. 2018). Previously stated, high intensity GICs can induce the high voltage fluctuations on the signalling channels that disrupt both short term and long-term impacts on performance of these systems.

At especially high altitudes such as countries falling in this region, Sweden, Finland and Russia, there is some indication of several anomalies in communication signalling systems have matched with geomagnetic storm conditions (Bothmer and Daglis 2007). There was also an unbalanced operation of automatic signalling and train control equipment that happened in 2004 on East-Siberian Railway (Ptitsyna et al. 2008). Specifically, signalling systems have registered an instance of false blockages (right-side failure) someplace no trains were existent (Wallerius 1982). The initiation for signal anomalies is understood by the induced currents originating from the ground during the event of especially strong geomagnetic storms. At these conditions, the natural electric field is big enough to decrease the operating voltage on the relay. Signalling is disrupted by a power outage as well. The measurement and analysis of electromagnetic interference on signalling issues in railway was studied (Niska et al. 2011).

Damages to track-circuit feed transformers might lead to a loss of the ability to detect train and, hence, to right-side failure (Dorman et al. 2008). Currents induced/directly coupled to a railway might trigger a wrong-side failure.
These conclusions are based not on thorough computations but on the basis of expert judgment. Experience shows that the failure physical characteristics may change when the train is in motion. The position of a train within the network could also change the probability of right vs wrongside failure. There exists an uncertainty on the behaviour of trains whether trains need to be stopped if there were no signals presented at the traffic light and to be communicated to train management systems (TMS) (Wik 2008). In the case of an extreme solar storm, several systems in the railway network that are dependent upon positioning of train can be also affected. This could lead to a risk of crashes of rolling stock. The accurate positioning of the trains is a vital for train control and signalling, and this can be disrupted via Global System for Mobile Communications - Railway (GSM-R) (Krausmann et al. 2015).

\subsubsection{Track circuits}

In Sweden, railways are fitted with track circuits using DC current. The electric track circuits are the crucial components in devices of the electric, automatic lock-out, and integrated traffic control because they provide a dependable communication link between rolling stock and TMS to ensure railway traffic safety. Track circuits normally consists of two joint connectors and isolation junctions for the purpose of electric disjunction of nearby track circuits, relays on the track and cable racks across the track relay and power that are in connection with rails.

Research conducted jointly by Natural Resources Canada (Eroshenko et al. 2010) and the Finnish Meteorological Institute has considered the possibility of effect of track circuits by geomagnetic disturbances. This study was conducted based on the knowledge experienced from geomagnetic induction in the power grid and pipelines from previous studies, and existing knowledge on possibility of AC interference in railway signalling. It was recommended for balanced track circuits that GIC and stray currents make a common-mode interference where the voltages in the two adjacent tracks cancel out each other without affecting the track-circuit operations. This is due to rate of change of magnetic field arises from the event (Hagpood 2011).

A separate condition happens for unbalanced track circuits described by a short circuit to the ground or between two tracks. The unbalanced track circuit can face differential-mode interference causing a distinct voltage. This variation in the difference in the voltage can impact rail operations. It was necessary to understand in more detail whether this could affect the level of geomagnetic disturbance impact on track-circuit operations. Initial studies showed that the susceptibility of track circuits to GICs/ stray currents can occur when a GIC produces a 
differential-mode interference in the unbalanced track circuits. It is undetermined at this point whether loading of GIC in track circuits may permanently have effectively changed from right-side failure to wrong-side failure, or vice versa, thus establishing a substantial safety risk (Krausmann et al. 2015). The direction of the railway tracks also needs to be considered because, it was theoretically calculated that, induced currents has major impact on west-east direction than south-north direction.

Northern railways are different in the anomalies reported. In several instances, through the main stage of a magnetic storm, below tracks, the relay voltage might steadily decrease, and the track relay was de-energized. The false occupation signal was also lived within 1 min or throughout the next $30 \mathrm{~s}$, the voltage steadily increased back to the minimal value. This behaviour occasionally persisted over several hours, following which usual procedure was regained. The feeding voltages on both the main and reserve feeders were supposed to be normal. Voltages variations were detected on both the relay and the rails and on both the relay and feedings ends. Only short and insulated sections were "fictitious occupied" and long tracks were usually not blocked (Liu et al. 2016). One reason for this phenomenon may be the manifestation of induced currents, i.e. GICs, in short rail circuits through strong and rapid variations of the geomagnetic field deprived of a reaction from the railway signalling (Wik et al. 2009).

The GICs on track circuits was simulated and it was reported that the voltage on the track relay coil of the twoelement two-position relay of the signal relay was reduced, and current phase deviated from ideal working value when storm happened, which may cause malfunction of the relay and railway signal lights to flash red light (Liu et al. 2015).

\subsubsection{Communication systems and commercial power in railways}

Generally, variations to the Earth's ionosphere can alter radio transmission signals in the high-frequency band (HF), for the reason that the ionosphere reflects a radio wave transmitted back to earth. Satellites were being designed and improved over the years to reduce the damage risk owing to surface charging. The signal to transmit with a satellite across a highly charged atmosphere layer in the event of a storm can be attenuated, but Infrastructure Managers do not depend on satellite communications for critical railway functions. Fibre optic long-distance cables also need to be reduced that effects to the leased network essential services for code lines, data and voice networks. Electric fields produced by geomagnetic storms can also cause in currents running into the transformers and utility lines. Modern signalling circuits are balanced, and usually intentionally ungrounded only common mode impact could lead to disruption (MacMillan et al. 2000).

\subsection{Potential future vulnerabilities}

Space weather events might affect the GNSS-originated position, navigation and timing data by influencing the satellite's function or registered position, together with influencing the user's capability to collect the transmitted signals. The receiver's tracing of GNSS signals might be lost through interference and noise. Positioning of train appears to be less of a challenge as GNSS is not the main technology utilized for this function (e.g. due to presence of tunnels). Nevertheless, various location-dependent functions, such as controlling the speed, detection of landslip and maintenance strongly dependent upon Global Positioning System (GPS) and other redundant systems must be deployed in crucial areas wherever necessary (Krausmann et al. 2015).

\section{Mitigation measures}

Some nations begun to address the risks linked to solar storms and started research in early warning detection, vulnerability issues and consequences and brainstorming best practices to reduce or eradicate the problem (Schieb and Gibson 2011). The economic considerations motivated important infrastructure operators with regard to operating risk mitigation policies in operation and maintenance that are reliant on prediction and forecasting of geomagnetic storm (Erinmez et al. 2002). One of those practices is to open up over-the-pole routes provided for civil aviation flight routes between Asia and North America through the early 1990s. Lately, these routes introduced new operational challenges which were not thought of these issues (AMA 2007). There is a need to investigate current mitigation procedures, mitigation cooperation endeavours, and industry particular risk mitigation measures for improved operation (Odenwald 2012). The below mitigation measures are for all transportation systems in general.

- With the early warning of the storm, there can be a possibility that the crucial infrastructure owners and operators can employ plans of contingency during severe geomagnetic storms.

- Integration of forecasting and awareness of solar storms through the international forum of electricity distribution grids would decrease risks posed by them and can implement operational mitigation strategies respective to their field (Krausmann 2011).

- Developers and prospective users of transportation need to observe solar storm difficulties and look for solutions 
in design and manufacturing to reduce the long-term impacts.

The major mitigation mechanisms schemes, techniques and approaches ranging for the railways that were described in Sect. 4 are stipulated below:

- Bearings that are instrumented might also be influenced, as their embedded electronic components are vulnerable to loading of GIC. This has a significant effect on the vibrational characteristics and changes the features. The lifetime of these bearings may be reduced because of the sudden accumulation of stresses, changing the maintenance issues over time. These effects may be sudden or progressive failures with an impact on maintenance limits over time (Krausmann et al. 2015).

- Mitigation is expected to be undertaken as early as possible to lessen the vulnerability on the railway grid. The cost seems to be moderate when associated to the economic impacts of a single storm. Particular measures should include (McMorrow 2011):

- Inserting a real-time GIC observers for every susceptible transformer, with methods to cut down AC power whenever necessary to prevent permanent destruction;

- Exploiting digital relays to prevent false tripping after GIC harmonics are appears to require essential tripping;

- Adding neutral-current-blocking-capacitors (NCBCs) together with shunt protection;

- The control of differential mode voltage is implemented to lessen interference to the track circuits and also reduce in design of rail to rail voltage, insulated joints, impedance bonds, surge arrestors, and ballast maintenance as an integral part of the railway maintenance.

- The track circuit would function at a frequency that was nowhere near to any specific power frequencies (or harmonics) and utilize a modulation method so that the recipient will know it was getting a real feed from the transmitter.

- If a storm is severe, a utility must respond in just a few seconds to lessen the obstruction by reducing line lengths, make sure of employing sufficient reactive measures, or by implementing other necessary measures to safeguard protective equipment does not disrupt the system when it does not have to function.

- Several utilities are implementing preventive and proactive procedures to observe the internal temperature of the oil in transformers and they are also monitoring the harmonic content using condition monitoring techniques of their power grids to find out when changes are happening. Nevertheless, a particular risk to the grids that supply power-particularly railway feeding systems (MacMillan et al. 2000).

\section{Forecasting of space weather events}

The main function of a nation's space weather infrastructure is to deliver consistent long-standing forecasts, though the significance of forecasts differs corresponding to specific industry. With a long-term forecasts and minimum false alarms, the different user groups might take necessary actions to mitigate/reduce the impacts of approaching solar disturbances from the Sun and to reduce on their economic and ecological environment. Presently, NOAA's Space Weather Prediction Center (SWPC) will be able to make likelihood forecasts of space weather events with differing levels of success. For instance SWPC can able to predict with a reasonable confidence the probability of occurrence of a geomagnetic storm or an X-class flare form one to three days early, while its ability to predict on par with short-term ( $<1$ day) or long-term forecasts of ionospheric disorders is poor where this information is necessary for GPS systems (Board 2008). Accurate predictions of the solar storm are required to reduce the influence of unpredictability on system operation and they are enhanced with current developments of science and technology.

Major components of ionosphere remote-sensing technology have been overshadowed by HF probes systems and sounding systems. Precise predictions in a short-term of performance of the system is to include the model process by updating with real-time data from sensors that investigate the temporal and spatial areas is of utmost importance. Kalman filters could be used for measurement errors by transforming the raw data into valuable data (Scherliess et al. 2004). Increased monitoring and considerably more research are needed to improve the knowledge. The selection of user requirements is a challenge that needs to be considered in the current trends of interest in a solar storm.

Several organizations are involved in solar storm research include forecasting. For example, the International Space Environment Service (ISES) is installed for monitoring near-real-time of World and to predict the activities in the space environment. NOAA has developed a set of Solar storm Scales that can provide guidance with various forms of solar-terrestrial disturbances. Swedish Institute of Space Physics is a research institute, funded by the Swedish government, which conducts fundamental research, education and related laboratory and observatory endeavours in space physics, space technology and atmospheric physics. Several companies have developed out in the recent years that are able to support customized solar 
storm products and essential services to prospective customers that are dependable for telecommunication systems, radio communications, etc. Defense associated endeavours provide the most advanced forecasting systems, but accessibility to the data and forecasting from the military organization could be problematical for common users. To expand the present market, more user education and awareness is necessary. Several telecommunication system administrators and operators are uninformed about the benefits of forecasting methodologies and also the accessibility to the appropriate forecasting systems (Odenwald 2012; Bothmer and Daglis 2007).

Due to nature of events, is also becoming increasingly challenging to predict or forecast the behaviour of the solar storm events on the Earth and its possible implications to the society. Vandegriff et al. (2005) developed forecasting algorithms to predict the influence of interplanetary shocks using artificial neural networks. Colak and Qahwaji (2009) developed an automated platform that can able predict the incoming activity of solar flares. Riley (2012) developed a model that could able to predict the likelihood of weather events using statistical model. Riley and Love (2017) estimated the likelihood of these extreme weather events in terms of storm size distributions. Camporeale et al. (2018) emphasized that it needs multidisciplinary approach to handle the machine learning approach in Space weather in terms of implementation and use of algorithms, knowledge discovery and forecasting. Murray (2018) also emphasized on application of ensemble techniques for prediction of space weather events. Camporeale (2019) provided some challenges in applying machine learning techniques in nowcasting and forecasting of these events such as information accessibility, grey-box, surrogate and uncertainty.

\section{Conclusions and recommendations}

Dependence on advanced technologies has made businesses, societies and governments are susceptible to the effects of the solar storm. The electric power industries have carried out considerable research on those impacts. Since the railway infrastructure involves the electric power, the exchange of information is beneficial to both industries. There is a need to raise awareness of solar storm in transport sector particularly that may have substantial social and economic consequences.

Apart from railways, the other transport sectors are also vulnerable to solar storm through navigation and radio communications. It is important to have several back-ups and redundant options with various technologies to the solar storm: for instance, the usage of e-LORAN and GPS for navigation. The optical fibres that are used for long distance communications on land and oceans are additional resistance to the solar storms. Nevertheless, wireless communications systems for example mobile phones, the internet and other technologies are still liable to interfering from powerful solar radio bursts. Such bursts can concurrently upset several railroad systems and might be extremely disrupting to the business endeavors.

\subsection{Railway operators}

The business partners operating in the railway sectors have different needs, but they should consider one of the following:

- To build protection mechanisms into the systems to reduce the risk of solar storms.

- To include temporary reconfiguration of the systems at risk in prior to mitigate the impact at the time of an event.

- To be ready and respond to solar storm problems at the time of a solar event.

- To analyse anything went erroneous during a solar storm event and improve these experiences to further reduce those in future.

Most of the above recommendations require access to the new type of services dealing with solar storm targeting the business needs, not just providing science level data and explanations. This suggests solar storm suggests prospects for new business activities:

- Providing essential services to assist other businesses to mitigate solar storm.

- Using solar storm knowledge and understanding to enhance the return of investment from systems that are affected by the solar storm.

There is also a need to perform further studies on the behaviour and consequences of geomagnetically induced current impacts on the transport system, with a special reference to railway sector, and more evaluation of dependences among systems w.r.t. safety and availability in the event of extreme geomagnetic activities. This would also support infrastructure managers; train operators and government authorities evaluate the advantages of guarding against solar storm and against the potential costs of inaction. This report presents an exploratory study and deeper research is needed to understand and develop mitigation measures against solar storms.

\subsection{Research focus}

Presently, the understanding and the knowledge of this kind of unexpected risk seems to be limited in the railway sector. Building awareness amongst infrastructure managers, train operations and government authorities is the 
earliest action in the direction of understanding and reducing the risk. Once this is done, potential susceptibilities and redundancies can also need to be evaluated to assist transport sectors. This could facilitate to protect their assets; development of mitigations measures as explained earlier and preparedness for such solar events. There is also a need to understand the potential effects of these additional currents in the existing assets. To that end, additional efforts can be made in incorporating these fluctuations in the design of these systems to make fool proof for not only space weather events but also for other extreme weather events (Campanyà et al. 2019). In addition, the government and disaster management authorities should also need to assess these events in the coming future and need to frame appropriate policies in defining the strategies to be adopted for the upcoming events (Grandhi et al. 2020).

\section{Discussion}

Space weather events may be described as low-frequency, high-consequence (LFHC) events. Several institutions and organizations have established comparatively decent efforts to get ready for and protect against destructive events that are properly recognized and expected to happen in other industrial sectors. Nevertheless, these low-frequency events, even if the possible destruction is huge, are usually few properly recognized and have not been given the appropriate consideration necessary to build up complex and costly protection measures (Board 2008). In this aspect, the railway sector can build up on the knowledge, experiences, research contributions and lessons acquired from the other influenced infrastructure sectors that have begun to confront the impending solar storm hazard with a few successes. It also needs to be admitted that shifting towards more and more automation and recent technological advancements that are heavily dependent upon electronic equipment in the forthcoming years might unintentionally create susceptibilities and vulnerabilities into the system. Because solar storm nature is a complicated event, introducing both disruptions and failures, knowledge research gaps should be closed.

Most important improvement has been achieved in knowledge of GIC over the past years, and the induced field is sufficiently robust about quantifying of the physical and materials procedures and impacts in managing the mitigation of the impending hazard. GIC is very critical to understand the behaviour and modelling of the the entire space weather chain, the actual measurable effects of the space weather phenomenon can create a societally pertinent tasks for scientists, physicists, engineers, and government policy makers. Multidisciplinary physics-based research and examinations with well-defined interactions and collaborations among various research disciplines should continue beyond the modelling and forecasting of GIC (Pulkkinen 2015).

The research of space weather events though quite mature in other systems but in the railway infrastructure, it is still in nascent stages. Due to the complexity and interdependencies of several systems, there is a lack of understanding and knowledge on the possible effects of space weather events on railway infrastructure. In addition to it, there are also few documented cases of solar events and because of this nature, it is difficult to correlate the failures or induced effects of the observed work orders in the databases to the events. The possible recommendation for the operators is to measure and observe the critical systems before the forecasted event so that there is a likelihood of obtaining anomalies and can find correlations. At the time of the event, several precautionary measures also need to be taken so that the impact can be reduced. These measures also to be brainstormed with experts to take appropriate measures to reduce the operating cost. In order to improve the robustness of the systems, experiments or simulations can be conducted on the critical systems.

Acknowledgements Open access funding provided by Lulea University of Technology.

Open Access This article is licensed under a Creative Commons Attribution 4.0 International License, which permits use, sharing, adaptation, distribution and reproduction in any medium or format, as long as you give appropriate credit to the original author(s) and the source, provide a link to the Creative Commons licence, and indicate if changes were made. The images or other third party material in this article are included in the article's Creative Commons licence, unless indicated otherwise in a credit line to the material. If material is not included in the article's Creative Commons licence and your intended use is not permitted by statutory regulation or exceeds the permitted use, you will need to obtain permission directly from the copyright holder. To view a copy of this licence, visit http://creativecommons. org/licenses/by/4.0/.

\section{References}

Baglietto E, Consilvio A, Di Febbraro A, Papa F, Sacco N (2018) A Bayesian Network approach for the reliability analysis of complex railway systems. In: 2018 International conference on intelligent rail transportation (ICIRT). IEEE, pp 1-6

Baker DN, Lanzerotti LJ (2016) Resource letter SW1: space weather. Am J Phys 84(3):166-180

Baker DN, Daly E, Daglis I, Kappenman JG, Panasyuk M (2004) Effects of space weather on technology infrastructure. Space Weather. https://doi.org/10.1029/2003SW000044

Board SS (2008) Severe space weather events-understanding societal and economic impacts: a workshop report. National Academies Press, Washington DC

Boteler DH, Pirjola RJ, Nevanlinna H (1998) The effects of geomagnetic disturbances on electrical systems at the Earth's surface. Adv Space Res 22(1):17-27 
Bothmer V, Daglis IA (2007) Space weather: physics and effects. Springer, Berlin

Campanyà J, Gallagher PT, Blake SP, Gibbs M, Jackson D, Beggan CD, Richardson GS, Hogg C (2019) Modeling geoelectric fields in Ireland and the UK for space weather applications. Space Weather 17(2):216-237

Camporeale E (2019) The challenge of machine learning in space weather nowcasting and forecasting. ArXiv preprint arXiv:1903. 05192

Camporeale E, Wing S, Johnson J, Jackman CM, McGranaghan R (2018) Space weather in the machine learning era: a multidisciplinary approach. Space Weather 16(1):2-4

Cander LR (2019) Space weather causes and effects. In: Ionospheric space weather. Springer, Cham, pp 29-58

Clark TD (2001) A review of the effects of space weather on groundbased technology. In: Space weather workshop: looking towards a European Space Weather Programme, Noordwijk, The Netherlands

Colak T, Qahwaji R (2009) Automated solar activity prediction: a hybrid computer platform using machine learning and solar imaging for automated prediction of solar flares. Space Weather $7(6): 1-12$

Colla I, Consilvio A, Olmi A, Romano A, Sciutto M (2018) High density-HD using ERTMS: the Italian solution for the Railway Traffic Management. In: 2018 IEEE international conference on environment and electrical engineering and $2018 \mathrm{iEEE}$ industrial and commercial power systems Europe (EEEIC/I\&CPS Europe). IEEE, pp 1-6

Consilvio A, Di Febbraro A, Meo R, Sacco N (2019a) Risk-based optimal scheduling of maintenance activities in a railway network. EURO J Transp Logist 8(5):435-465

Consilvio A, Sanetti P, Anguita D, Crovetto C, Dambra C, Oneto L, Sacco N (2019b) Prescriptive maintenance of railway infrastructure: from data analytics to decision support. In: 2019 6th international conference on models and technologies for intelligent transportation systems (MT-ITS). IEEE, pp 1-10

Daglis T, Konstantakis KN, Michaelides PG (2019) Solar events and economic activity: evidence from the US telecommunications industry (1996-2014). Phys A Stat Mech Appl 534:120805

Dorman LI, Ptitsyna NG, Villoresi G, Kasinsky VV, Lyakhov NN, Tyasto MI (2008) Space storms as natural hazards. Adv Geosci. https://doi.org/10.5194/adgeo-14-271-2008

Eastwood JP, Hapgood MA, Biffis E, Benedetti D, Bisi MM, Green L, Burnett C (2018) Quantifying the economic value of space weather forecasting for power grids: an exploratory study. Space Weather 16(12):2052-2067

Elovaara J, Lindblad P, Viljanen A, Mäkinen T, Pirjola R, Larsson S, Kielén B (1992) Geomagnetically induced currents in the Nordic power system and their effects on equipment, control, protection and operation. CIGRÉ General Session 1992, Paris, Aug 31-Sept 5, 1992, No. 36-301, pp 10

Erinmez IA, Kappenman JG, Radasky WA (2002) Management of the geomagnetically induced current risks on the national grid company's electric power transmission system. J Atmos Solar Terr Phys 64(5-6):743-756

Eroshenko EA, Belov AV, Boteler D, Gaidash SP, Lobkov SL, Pirjola R, Trichtchenko L (2010) Effects of strong geomagnetic storms on Northern railways in Russia. Adv Space Res 46(9):1102-1110

Fällman C (1999) Signalteknisk information. BT95088. Banverket

Forte B, Vani BC, Smith N, Monico JF, Ruffenach A, Flintoft I, Koulouri A (2018) Space weather disruptions to satellite navigation and telecommunications in the case of interdependent services. In: 15th European space weather week

Garmabaki AHS, Marklund S, Thaduri A, Hedström A, Kumar U (2020) Underground pipelines and railway infrastructure-failure consequences and restrictions. Struct Infrastruct Eng 16(3):412-430

Girgis R, Vedante K (2012) Effects of GIC on power transformers and power systems. In: Transmission and distribution conference and exposition (T\&D), 2012 IEEE PES. IEEE, pp 1-8

Goodman JM (2006) Space weather and telecommunications, vol 782. Springer, Berlin

Grandhi SA, Plotnick L, Hiltz SR (2020) An internet-less world? Expected impacts of a complete internet outage with implications for preparedness and design. In: Proceedings of the ACM on human-computer interaction, 4(GROUP), pp 1-24

Grant A, Shaw G, Ward N (2012) The effect of space weather on maritime aids-to-navigation service provision. Annu Navig 19(1):49-66

Hagpood M (2011) European integrated research infrastructures for monitoring and predicting space weather. IMPRESS. I3

Hanslmeier A (2010) The sun and space weather. Springer, Berlin, pp 233-249

Hapgood M (2017) Satellite navigation-amazing technology but insidious risk: why everyone needs to understand space weather. Space Weather 15(4):545-548

Jo O, Kim YK, Kim J (2017) Internet of things for smart railway: feasibility and applications. IEEE Internet Things $\mathbf{J}$ $5(2): 482-490$

Johansson J, Hassel H, Cedergren A (2011) Vulnerability analysis of interdependent critical infrastructures: case study of the Swedish railway system. Int J Crit Infrastruct 7(4):289-316

Kans M, Galar D, Thaduri A (2016) Maintenance 4.0 in railway transportation industry. In: Proceedings of the 10th World congress on engineering asset management (WCEAM 2015). Springer, Cham, pp 317-31

Kappenman J (2010) Geomagnetic storms and their impacts on the US power grid. Metatech, Goleta

Koons HC, Mazur JE, Selesnick RS, Blake JB, Fennell JF (1999) The impact of the space environment on space systems (No. TR-99 (1670)-1). Aerospace Corp El Segundo Ca El Segundo Technical Operations

Kraftnät S (2011) Skydd mot geomagnetiska stormar Elektromagnetisk påverkan på kraftsystemet. Dnr 2011/805

Krausmann E (2011) The space-weather awareness dialogue: findings and outlook. JRC Scientific and Technical Reports, European Commission, Joint Research Center Ispra, Italy

Krausmann E, Andersson E, Murtagh W, Mitchison N (2013) Space weather and power grids: findings and outlook. EUR 26370

Krausmann E, Andersson E, Russell T, Murtagh W (2015) Space weather and rail: findings and outlook. JRC science and policy reports, European Union, Luxembourg, EUR 27523

Lam HL, Boteler DH, Trichtchenko L (2002) Case studies of space weather events from their launching on the Sun to their impacts on power systems on the Earth. Ann Geophys 20(7):1073-1079

Lanzerotti LJ (2001a) Space weather effects on technologies. Space Weather 125:11-22

Lanzerotti LJ (2001b) Space weather effects on communications. In: Space storms and space weather hazards. Springer Netherlands, pp 313-334

Liu LG, Yu YF, Zong W, Ma CY, Ma YF (2015) Simulation calculation about interference of geomagnetic storms on track circuit equipment. J China Railw Soc 8:009

Liu L, Ge X, Zong W, Zhou Y, Liu M (2016) Analysis of the monitoring data of geomagnetic storm interference in the electrification system of a high-speed railway. Space Weather 14(10):754-763

Lundstedt H (2006) Solar activity modelled and forecasted: a new approach. Adv Space Res 38(5):862-867 
MacMillan RK, Keefe RL, Perala RA (2000) Geomagnetic storms and the possible effects on the railroad system. In: AREMA proceedings of the 2000 annual conference

McMorrow D (2011) Impacts of severe space weather on the electric grid. JASON, Virginia, 22102-7508

Moldwin M (2008) An introduction to space weather. Cambridge University Press, Cambridge

Morant A, Wisten Å, Galar D, Kumar U, Niska S (2012) Railway EMI impact on train operation and environment. In: International symposium on electromagnetic compatibility-EMC EUROPE. IEEE, pp 1-7

Murray SA (2018) The importance of ensemble techniques for operational space weather forecasting. Space Weather 16(7):777-783

Niska S (2008) Measurements and analysis of electromagnetic interferences in the Swedish railway systems. Doctoral Thesis (2008:76)

Niska S, Schunnesson H, Kumar U (2011) Measurements and analysis of electromagnetic interference in a railway signal box-a case study. Int J Reliab Qual Saf Eng 18(03):285-303

Odenwald S (2012) Space weather-impacts, mitigation and forecasting. Visiting scientists program, University Corporation for Atmospheric Research, Boulder, Colorado

Oughton EJ, Skelton A, Horne RB, Thomson AW, Gaunt CT (2017) Quantifying the daily economic impact of extreme space weather due to failure in electricity transmission infrastructure. Space Weather 15(1):65-83

Patt A, Pfenninger S, Lilliestam J (2013) Vulnerability of solar energy infrastructure and output to climate change. Clim Change 121(1):93-102

Pesnell WD (2015) Solar dynamics observatory (SDO). Springer, Berlin, pp 179-196

Piccinelli R, Krausmann E (2014) Space weather and power grids-a vulnerability assessment. European Union, Luxembourg, pp $1-53$

Pirjola R (2000) Geomagnetically induced currents during magnetic storms. IEEE Plasma Sci 28(6):1867-1873

Pirjola R (2005) Effects of space weather on high-latitude ground systems. Adv Space Res 36(12):2231-2240

Pirjola R, Viljanen A, Amm O, Pulkkinen A (1999) Power and pipelines (ground systems). In: Proceedings of a workshop on space weather, Nov 1998, ESA WPP, vol 155

Ptitsyna NG, Kasinskii VV, Villoresi G, Lyahov NN, Dorman LI, Iucci N (2008) Geomagnetic effects on mid-latitude railways: A statistical study of anomalies in the operation of signaling and train control equipment on the East-Siberian Railway. Adv Space Res 42(9):1510-1514

Pulkkinen A (2015) Geomagnetically induced currents modeling and forecasting. Space Weather 13:734-736. https://doi.org/10.1002/ 2015SW001316
Pulkkinen A, Lindahl S, Viljanen A, Pirjola R (2005) Geomagnetic storm of 29-31 October 2003: Geomagnetically induced currents and their relation to problems in the Swedish high-voltage power transmission system. Space Weather 3(8):1-19

Pulkkinen A, Kuznetsova M, Ridley A, Raeder J, Vapirev A, Weimer D, Wiltberger RS, Millward M, Rastätter GL, Hesse M (2011) Geospace environment modeling 2008-2009 challenge: ground magnetic field perturbations. Space Weather 9(2):1-13

Riley P (2012) On the probability of occurrence of extreme space weather events. Space Weather 10(2):1-12

Riley P, Love JJ (2017) Extreme geomagnetic storms: probabilistic forecasts and their uncertainties. Space Weather 15(1):53-64

Roy B, Paul A (2013) Impact of space weather events on satellitebased navigation. Space Weather 11(12):680-686

Scherliess L, Schunk RW, Sojka JJ, Thompson DC (2004) Development of a physics-based reduced state Kalman filter for the ionosphere. Radio Sci 39(1):1-12

Schieb PA, Gibson A (2011) Geomagnetic storms. Technical report. http://www.oecd.org/dataoecd/57/25/46891645.pdf

Thaduri A, Galar D, Kumar U (2015) Railway assets: a potential domain for big data analytics. Proc Comput Sci 53:457-467

Thaduri A, Verma AK, Kumar U (2020) Maintenance of railway infrastructure using cyber-physical systems. In: Decision analytics applications in industry. Springer, Singapore, pp 521-540

Trichtchenko L, Boteler DH (2001) Specification of geomagnetically induced electric fields and currents in pipelines. J Geophys Res Space Phys 106(A10):21039-21048

Vandegriff J, Wagstaff K, Ho G, Plauger J (2005) Forecasting space weather: predicting interplanetary shocks using neural networks. Adv Space Res 36(12):2323-2327

Vennerstrom S, Lefevre L, Dumbović M, Crosby N, Malandraki O, Patsou I, Moretto T (2016) Extreme geomagnetic storms1868-2010. Sol Phys 291:1447-1481

Wallerius A (1982) Solen gav Sverige en strömstöt (in Swedish). Ny Teknik - Teknisk Tidskrift 29:3

Wästgärds P-E (2000) Jorden kommer att drabbas av jordmagnetiska störningar. Kulmen troligen i mars år 2000. BVM 599.031. Banvkerket

Watermann J (2007) The magnetic environment-GIC and other ground effects. In: Space weather. Springer Netherlands, pp 269-275

Wik M (2008) The Sun, Space weather and effects. Lund University, Lund

Wik M, Pirjola R, Lundstedt H, Viljanen A, Wintoft P, Pulkkinen A (2009) Space weather events in July 1982 and October 2003 and the effects of geomagnetically induced currents on Swedish technical systems. Ann Geophys 27(4):1775-1787

Publisher's Note Springer Nature remains neutral with regard to jurisdictional claims in published maps and institutional affiliations. 